\title{
Para além da substância: considerações sobre o sujeito na condição da toxicomania $^{*}$
}

\section{Mônica Medeiros Kother Macedo' \\ Carolina Neumann de Barros Falcão Dockhorn \\ Pontifícia Universidade Católica do Rio Grande do Sul, Porto Alegre - RS - Brasil}

Paula Kegler

Faculdades Integradas de Taquara (Taquara) e Pontifícia Universidade Católica do Rio Grande do Sul

(Porto Alegre) - RS - Brasil

\begin{abstract}
Resumo: $O$ aumento do consumo de drogas e seus efeitos subjetivos configuram um problema epidêmico de saúde pública. Este artigo apresenta os resultados de um estudo qualitativo acerca da condição subjetiva de oito jovens toxicômanos que buscaram auxílio em instituições destinadas ao tratamento de dependentes químicos. $\mathrm{Na}$ metodologia da análise interpretativa de dados coletados em entrevistas, foi utilizado o referencial psicanalítico. A precariedade das relações primordiais denunciou construções subjetivas marcadas por abandono e desamparo. A compreensão acerca da condição do sujeito, em sua relação com o objeto droga, revelou a intensa dor psíquica que encontra, na anestesia oferecida pelo tóxico, uma estratégia de enfrentamento. Constatou-se, no relato dos participantes deste estudo, como as intensidades vivenciadas precocemente e não tramitadas pelo psiquismo encontram, como forma de descarga, a via do ato. A fragilidade psíquica dos sujeitos entrevistados permite reafirmar a necessária ampliação nas estratégias usuais de intervenção sobre o fenômeno da drogadição.
\end{abstract}

Palavras-chave: toxicomania; sujeito; dor psíquica; psicanálise; saúde pública.

\section{BEYOND THE SUBSTANCE: CONSIDERATIONS ABOUT THE SUBJECT IN THE DRUG ADDICTION CONDITION}

\begin{abstract}
The increase in the use of drugs and their subjective effects are an epidemic problem for public health. This paper presents the results of a qualitative study on the subjective condition of eight young addicts that have sought help in rehabilitation clinics. The methodology of interpretive analysis of data collected from the interviews used the psychoanalytic theory. The precariousness of primordial relationships resulted in a construction of subjectivity marked by abandonment and helplessness. The understanding of the subject condition and his relation with the object drug reveals a psychic pain that meets, in the anesthesia offered by the drug, a coping strategy. It was found that the intensity of the early experiences in life, and not psychic elaborated, meet, as a form of discharge, the path of the act. The observed psychic fragility reaffirmed the necessity for an expansion of strategies of dealing with drug addiction.
\end{abstract}

Keywords: addiction; subject; psychic pain; psychoanalysis; public health.

* Agradecemos o fomento que viabilizou a realização desta pesquisa por meio do Edital do CNPq MCT $n^{\circ}$ 02/2010 Ciências Humanas, Sociais e Sociais Aplicadas.

${ }^{1}$ Endereço para correspondência: Mônica Medeiros Kother Macedo, Avenida Ipiranga, 6.681, prédio $11,9^{\circ}$ andar, sala 926, Partenon - Porto Alegre - RS - Brasil. CEP: 90619-900. E-mail: monicakm@pucrs.br. 
PARA ALLÁ DE LA DROGA: CONSIDERACIONES SOBRE EL SUJETO EN LA CONDICIÓN DE LA TOXICOMANÍA

\begin{abstract}
Resumen: El aumento del consumo de drogas y sus efectos subjetivos configuran un problema de salud pública. Este artículo presenta resultados de un estudio cualitativo acerca de la condición subjetiva de ocho jóvenes toxicómanos que buscaron tratamiento para la dependencia de sustancias químicas. En la metodología del análisis interpretativo de datos colectados en entrevistas se utilizó el referencial psicoanalítico. La precariedad de las relaciones primordiales denunció construcciones subjetivas marcadas por abandono y desamparo. La comprensión acerca de la condición del sujeto, en su relación con el objeto droga, reveló el dolor psíquico que encuentra una estrategia de enfrentamiento en la anestesia ofrecida por lo que es tóxico. Se constató como las intensidades experimentadas precozmente y no tramitadas por el psiquismo encuentran, como forma de descarga, la vía del acto. La fragilidad psíquica de los sujetos entrevistados permite reafirmar la necesaria ampliación de las estrategias de intervención que son usuales sobre el fenómeno de la drogadicción.
\end{abstract}

Palabras clave: toxicomanía; sujeto; dolor psíquico; psicoanálisis; salud pública.

O uso de drogas está presente em toda a história da humanidade, e seus indicadores de produção e consumo seguem alarmantes. O Relatório mundial sobre drogas 2012 apresentou a estimativa de que 230 milhões de pessoas ( $5 \%$ da população mundial adulta) fizeram uso de drogas pelo menos uma vez em 2010. De acordo com esse documento, o número de usuários problemáticos alcançava em torno de 27 milhões de pessoas ( $0,6 \%$ da população adulta) (Escritório das Nações Unidas sobre Drogas e Crime, 2012). Em relação ao Brasil, o relatório observa que o uso de drogas é mais difundido na metade sul, todavia apresenta a ressalva de que "a falta de dados novos para este país impede um melhor entendimento do impacto nas estimativas regionais" (Escritório das Nações Unidas sobre Drogas e Crime, 2012, p. 11). De fato, o Brasil é um país que enfrenta profundas dificuldades em âmbito socioeconômico, e o fenômeno do consumo e tráfico de drogas ocupa espaço privilegiado nessa gama de problemas sobre os quais urgem soluções efetivas. Até 1998, o governo federal preconizava políticas de repressão ao tráfico em detrimento da prevenção do uso de drogas, pois as estratégias de tratamento assemelhavam-se ao modelo hospitalar. Atualmente, com a criação dos Centros de Atenção Psicossocial Álcool e Drogas (Caps AD), o atendimento consiste em prática clínica e ambulatorial, visando à reinserção social dos usuários, com internações apenas em situações de extrema necessidade (Lei $\left.n^{\circ} 11.343,2006\right)$.

Sabe-se que a dependência química é uma condição multideterminada a partir de influências biológicas, genéticas, psíquicas, ambientais e culturais. Segundo Conte (2003, p. 16), deve-se fazer uma crítica ao modelo que embasa serviços psiquiátricos e religiosos de tratamento, cuja intervenção privilegia o comportamento da abstinência, já que sua ideologia fundamental é a da contenção e do controle, não objetivando "uma modificação da relação do sujeito com a droga e sua significação na vida psíquica". Nesse sentido, tomando os aportes da psicanálise no multifatorial fenômeno da droga, surge um profundo questionamento acerca dos fatores que levam um indivíduo a necessitar tão completamente de uma substância e, sobretudo, de como é possível alicerçar sobre os pressupostos psicanalíticos a possibilidade efetiva de intervenção sustentada por uma 
escuta singular. Na justificativa da necessária inserção da psicanálise no campo da drogadição, Torossian (2004) apresenta relevante oposição à compreensão de que o tratamento psicoterapêutico para indivíduos dependentes de drogas visa à manutenção de um estado de abstinência que enfatiza a droga no processo de cura na medida em que desconsidera o sujeito. A autora afirma, portanto, que a psicanálise não trata da dependência química, mas sim do sujeito que sofre de toxicomania, isto é, de uma condição com formação sintomática crônica que evidencia um sujeito na relação de exclusividade com a droga.

Reforça-se, então, a importância de incluir, no campo de estudos sobre adição e na proposição de estratégias de enfrentamento à questão, a consideração ao sujeito da adição. Assim, sustenta-se esta investigação da dependência química não pela vertente da incurabilidade, mas assentada na compreensão de um funcionamento psíquico no qual a droga torna-se um objeto de necessidade (e não de desejo). Por isso, optou-se pelo emprego de expressões como toxicomania (que evidencia a relação tóxica do sujeito com o objeto droga) e drogadição (que aponta para o estado de adição - escravidão, em sua etimologia). Ressalta-se que nem todo o uso de drogas deve ser considerado como toxicomania, já que esta se instala quando o sujeito aprisiona-se numa relação exclusiva, sem tolerância de adiamentos ou substituições, com a droga. Diante desse cenário, o presente artigo apresenta os resultados de um estudo que abordou a condição subjetiva de jovens toxicômanos residentes em Porto Alegre e na região metropolitana. A partir de aportes psicanalíticos, busca-se contribuir para a reflexão a respeito da condição do sujeito em sua relação com o objeto droga.

\section{Método}

Optou-se, nesta pesquisa, pelo pressuposto metodológico qualitativo, no qual os dados foram coletados numa interação interpessoal, tomando como ponto de partida os significados que o sujeito e/ou pesquisador atribuem ao fato (Campos, 2001). Vale ressaltar que todas as exigências éticas da regulamentação de pesquisas com seres humanos foram atendidas.

\section{Participantes}

Participaram da pesquisa oito sujeitos do sexo masculino e feminino, localizados por conveniência, com idade entre 15 e 24 anos, independentemente de raça, nível socioeconômico ou escolaridade, que buscaram auxílio em instituições destinadas ao tratamento de saúde física e/ou mental.

\section{Materiais e procedimentos}

Os dados deste estudo foram coletados por meio de uma série de quatro entrevistas semiestruturadas de questões abertas que compuseram o estudo de caso de cada participante. As entrevistas foram realizadas nas dependências de quatro instituições participantes do estudo (um Caps AD, uma comunidade terapêutica religiosa, um hospital 
geral e uma organização não governamental de assistência comunitária). O tempo médio de duração das entrevistas variou de 30 a 60 minutos. A série de entrevistas seguiu o seguinte roteiro: na primeira, o objetivo central foi conhecer a história de vida do participante; na segunda, identificaram-se, do ponto de vista dos participantes, as associações acerca dos fatores relacionados ao uso de substâncias psicoativas e às experiências quanto ao consumo propriamente dito; na terceira, exploraram-se as expectativas e os significados atribuídos pelos participantes ao tratamento; e finalmente, na quarta e última entrevista, foi oportunizado ao participante falar sobre o que quisesse e/ou o que não fora suficientemente abordado nos encontros anteriores.

Para a análise dos dados obtidos no estudo, utilizou-se o método proposto por Erickson (1997) denominado "análise interpretativa", no qual o trabalho interpretativo com dados obtidos possibilita que as perguntas centrais da investigação refiram-se a aspectos que não são óbvios ou triviais. Ao final do estudo, são produzidas assertivas que contemplam a temática identificada mediante trabalho metodológico com as entrevistas. As assertivas são acompanhadas de comentários interpretativos que permitem ao leitor acompanhar o pesquisador no processo de perceber quais são os detalhes, dentre os vários sentidos semânticos das falas dos participantes, que este considerou proeminentes e as interpretações que Ihes atribuiu (Erickson, 1997). Com a psicanálise como fonte de sustentação teórica para a análise dos dados, destaca-se a escuta dos sentidos ocultos das falas dos sujeitos.

\section{Resultados e discussão}

A partir do trabalho com o material das entrevistas dos oito participantes, chegou-se à construção de três asserções, abordadas a seguir.

\section{O contexto subjetivo: precariedade nas relações primordiais}

Nos relatos dos participantes, um dos aspectos que se repetem refere-se à precariedade das relações primordiais. São histórias de abandonos vividos nas realidades material e psíquica e de experiências cotidianas de descuido e distanciamento em relação às figuras parentais. A participante E. (23 anos) apresenta as relações primordiais que marcaram a sua história, justificando o encontro com a droga: "Depois dos 11 anos, eu comecei a ir pra festa, pra farra; aí com 12 me casei, me casei pra fugir de casa. Era muita briga! Uma vez, apanhei do meu pai com um umbigo de boi, já apanhei de corrente também [...]". Pode-se pensar que o fugir de casa a qualquer custo põe em evidência a violência e o descuido referidos pela participante. Nesse mesmo sentido, C. (24 anos) relata que nunca teve uma boa relação com seus pais. Fugia sistematicamente de casa "porque o meu pai me batia. Me batia porque eu aprontava e fugia. Daí quando eu voltava, ele pegava e me batia de novo. Aí eu dava um tempo, assim, mais ou menos o quê... mais duas, três semanas e fugia de novo".

A psicanálise aborda o tema do exercício das funções parentais como estruturantes do psiquismo. Assim, muito mais do que considerar a presença real dos pais, considera-se a qualidade dos encontros com essas figuras. É inegável a condição inicial do ser humano 
no que diz respeito à vital necessidade de cuidados despendidos por outra pessoa para que possa, a priori, sobreviver. Seu estado inicial é experienciado, então, como uma situação de desamparo, sendo fundamentais as experiências intersubjetivas para a constituição do aparelho psíquico. O participante $\mathrm{C}$. retrata a impossibilidade dos cuidadores de ocuparem seus lugares de objetos primordiais na via do cuidado. Ao bater, o pai de C. deixava-o ainda mais atordoado e sem outra saída que não a de fugir novamente. Já a mãe, "ela cansava de passar a mão por cima de mim. Me livrava das surras do meu pai, me emprestava dinheiro quando eu precisava pra comprar droga. [E ela sabia que era pra usar?] Sabia. Tava na cara, né?". Ao acobertar o uso da substância ou mesmo tentar protegê-lo da violência paterna, a mãe denunciava a impossibilidade de ocupar seu lugar, uma vez que não possibilitava a construção de vias a partir das quais poderiam ser garantidas formas de relação distintas das formas violentas de ligação com os objetos (quer fosse a droga, quer fosse o pai).

O participante J. (18 anos) foi dado aos nove dias pela mãe para ser criado pela avó, não conhece o pai, parou de estudar e passa os dias na rua. O que J. evidencia é a angústia que o impede de ficar em casa, momento em que precisa deparar-se com sua história e com quem não cuida dele. A angústia o coloca na rua e o impulsiona às drogas. Nesse cenário, S. (15 anos) apresenta relações primordiais que não garantem a alteridade e denunciam a impossibilidade de oferecer ao menino uma organização do seu lugar de criança e adolescente:

Desde novo, eu estava sempre na rua. Meu pai andava comigo, me levava nas festas. Daí ele comprou um carro para mim quando eu tinha 15 anos. Só que eu não podia usar todos os dias, mas usava pra sair. Daí um dia encontrei um parceiro meu, e ele ia lá na boca buscar, aí eu fui junto.

Foram constatadas, nos relatos dos sujeitos, situações traumáticas com seus objetos primordiais, impossíveis de elaboração. O jovem D. (18 anos), por exemplo, foi abandonado pela mãe, usuária de drogas e prostituta, a qual se valia dele para obter ajuda da irmã, que passou a cuidar do menino. A mãe de D. aparecia quando precisava de dinheiro, afirmando que estava de volta para passar a cuidar do filho. Logo após conseguir o dinheiro, sumia novamente. Ao contar sua história, D. refere o sentimento que se repete em suas relações: "um desprezo que eu sentia... era como se eu quisesse conversar com alguém e... e, tipo, aquela pessoa nunca tivesse tempo pra ti". Da mesma forma, E. refere também situações traumáticas que marcaram sua história. Apesar de ter uma aparente família estruturada, E. conta das repetidas vezes que a mãe ia viajar a trabalho, sem que nada fosse explicado a ela:

Era sempre muita disputa de carinho porque a mãe trabalhava fora. Trabalhava numa casa de família, só que a mulher gostava de viajar e levava ela sempre porque confiavam nela. Então ela levava a G. [irmã mais velha], mas eu nunca soube por quê. No colégio, sempre chamavam as mães, mas eu não tinha a minha mãe ali no lado. Pensei que a mãe nunca ia voltar pra mim. 
Desde as proposições teóricas da psicanálise, tem-se que o encontro primordial do bebê desamparado se dá com objetos que constituem a função materna. Como afirma Hornstein (2008), o Eu se constitui desde os outros primordiais, os quais, por meio dos cuidados demandados, criam condições de excitação, frustração, atribuição de sentido, gratificação e proteção. Para o autor, é do ritmo da presença-ausência que resulta o outro ser presença estruturante e não presença arrasadora. Ao longo do processo de complexização do Eu (consolidação da noção de identidade), é fundamental que haja, também, o encontro com a função paterna. Para a psicanálise, a noção de pai refere-se à representação de limites, internalização de leis, instauração do superego e sustentação da díade mãe-bebê. O pai é uma entidade imersa no campo simbólico e designa uma função que, ao mesmo tempo, estrutura e ordena o psiquismo. Assim, no processo de constituição do sujeito, a função paterna adquire valor estruturante que diz respeito a uma operação que interdita e representa a lei, pois apresenta os imprescindíveis limites e restrições aos desejos (Hornstein, 2008).

Relatos como os de E. e C. colocam em evidência uma importante precariedade no registro da interdição tão necessária à constituição psíquica ordenada pela palavra e pelo acesso ao mundo simbólico. Ao personificarem a interdição de forma arbitrária, os objetos primordiais mostram-se impedidos de exercer suas funções estruturantes. Dessa forma, ao imporem atos de violência (como nas histórias de E. e C.) ou ao desmentirem a condição de desamparo dos filhos (a mãe de C. que finge não saber do uso de drogas, e o pai de S. que compra um carro para o adolescente de 15 anos), são impostas intensidades a esses sujeitos que os atordoam e os aprisionam nas fragilidades do si mesmo. Assim, muitas das histórias dos sujeitos toxicômanos podem ser descritas tanto como uma vivência de indiferença (Moraes \& Macedo, 2011) quanto como um aprisionamento ao investimento narcísico do outro. Nesses casos, o outro não se oferece como registro de alteridade, produzindo profundos comprometimentos no capital subjetivo do sujeito, assim como em seu potencial simbólico. Os efeitos decorrentes das falhas primordiais no encontro do sujeito com o outro, no exercício da função materna e da função paterna, instauram fragilidades na constituição do narcisismo. A precariedade da noção do si mesmo compõe o segundo eixo de compreensão dos dados.

\section{Precariedade no processo de construção do si mesmo}

Evidenciou-se, no trabalho de investigação, a necessidade de atentar às singularidades presentes na história de vida de cada participante, a fim de compreender a fragilidade de recursos psíquicos percebidos na condição de toxicomania. A precariedade dos recursos de enfrentamento fez-se presente a todo tempo nas entrevistas realizadas. A participante E., por exemplo, ao contar sobre o seu encontro com as drogas, fala de como sempre se sentiu sozinha. Após um silêncio, E. propõe interromper a entrevista. Denuncia, com isso, a ausência de palavras que representem sua angústia: 
E.: Acho que por hoje chega, né?

Entrevistadora: Tu não queres mais falar?

E.: Não.

Entrevistadora: E tu consegues me dizer o que tu estás sentindo?

E.: [silêncio] Meio triste... [silêncio].

Entrevistadora: E quando bate essa tristeza, perde a vontade de falar?

E.: Perde... [silêncio].

Entrevistadora: Tu quer tentar me dizer o que está na tua cabeça?

E.: Muito ódio... muito ódio [...].

Já D. consegue, de alguma forma, nomear sua impossibilidade de acesso ao que se passa dentro dele: "Agora me sinto mais... agora, como é que eu vou te dizer... vazio. Eu me sinto mais vazio... vazio, tipo... como é que eu vou te dizer? Mais vazio... sem aquele ódio que eu tinha...". Percebe-se que o recurso disponível não é o da elaboração, mas, sim, o do desligamento da carga afetiva. O participante $\mathrm{D}$. não deixa de ter ódio porque conseguiu pensar-se ou por compreender o incômodo; só deixa de ter ódio por sentir-se esvaziado.

Desde a perspectiva freudiana, o Eu não está presente nos primórdios da vida do sujeito, e sua construção dar-se-á por meio de uma nova ação psíquica (narcisismo). O Eu não se constituirá se o sujeito não for tomado como objeto de investimento amoroso por outro. Considerar a temática da constituição do Eu conduz necessariamente à atenção aos primeiros laços afetivos com o mundo, aos desejos e às ilusões que foram projetados sobre a criança e à forma como ela foi desejada. $\mathrm{O}$ amor materno precisa ser motor e dique da vida pulsional. O Eu como unidade psíquica é constituído pelas vivências de satisfação e de dor. Seu trabalho é inibir ou adiar a descarga psíquica e permitir o processo secundário. Se houver demasiadas satisfações da necessidade carente de amor ou se esta for postergada além do suportável, ou ainda houver importante transmissão das angústias da mãe, haverá alteração desse processo, que é forjador do narcisismo sadio. Por sua vez, o narcisismo patológico evidencia uma falta crônica de investimentos amorosos parentais que se traduz em uma falta de amor próprio e em uma importante precariedade do Eu. Quando a sobrevivência psíquica não está assegurada, pois não se constituiu a transicionalidade, o Eu, em vez de estar regido pela linguagem, simbolização e criatividade, torna-se árido por descargas somáticas, atos ou pela depressão. Nessa perspectiva, afirma-se o caráter fundamental de instauração do mundo pulsional, por serem essas experiências as responsáveis pela fundação do psiquismo representacional. Logo, como aponta Savietto (2010), é fundamental reconhecer o quanto a noção de desamparo remete aos limites e às possibilidades da representação.

Pensa-se, a partir da análise das histórias de vida escutadas, que o sujeito drogadito encontra-se aprisionado na necessidade de uma constante presença que mascara $o$ intenso desamparo experimentado. Ante a necessidade do outro, não suprida no campo da alteridade, encontra no consumo do objeto droga um circuito autocentrado de lidar com sua dor. A engrenagem lhe permite, por um período, manter a ilusão de 
autossuficiência, ao gerir sozinho as doses necessárias de encontro com a substância para descarregar a angústia. Sabe-se que a história do sujeito humano é feita de encontros e desencontros com o objeto. É a partir dessa perspectiva que o psiquismo vai se constituindo, sob diferentes modalidades de enfrentamento da presença-ausência do outro, além de seus efeitos qualitativos, que vão deixando atrás de si registros psíquicos que contam de uma história pulsional. Assim, chega-se à necessidade de examinar o papel que o objeto droga ocupa na economia psíquica dos sujeitos toxicômanos, tema que compõe o terceiro eixo de análise dos dados.

\section{Modalidades de relação com o objeto droga}

No estudo realizado, evidenciou-se que o campo das subjetividades marcadas pela realidade da toxicomania apresenta-se como multifatorial em termos de sua etiologia. De fato, a psicanálise destaca a heterogeneidade presente nas relações entre o sujeito e seu corpo por meio do uso do objeto droga. A participante E. refere o estado absoluto de relação com a droga, bem como o uso do próprio corpo como única forma encontrada de expressar as intensidades que a atordoa desde dentro. Ela relata sua condição quando chegou ao local onde está internada: "Estava com $22 \mathrm{~kg}$ quando vim pra cá, não conseguia caminhar de tão magra, vim carregada". Conta que "roubava para fumar pedra", "traficava pra conseguir algum" e "não dormia, não comia... de tu só querer fumar, só fumar. Não dava ânimo para nada".

É necessário, pela impossibilidade de desvinculação entre corpo e psiquismo, abordar as toxicomanias como formas de colocar em condição de extrema vulnerabilidade o corpo biológico. O lugar destinado ao somático, nos casos de toxicomanias graves, é preponderante, uma vez que estas evidenciam o paradoxo presente na operação do farmakon (Le Poulichet, 2005). Essa expressão designa a necessidade de remediar uma dor psíquica insuportável envenenando-se para se medicar perante uma dor psíquica intensa. Nesse uso, por meio de um objeto droga que o envenena organicamente, o sujeito pode ocasionar sua morte biológica. O feitiço de farmakon é capaz de tornar o sujeito um alquimista, transformando a dor de um narcisismo absoluto (Le Poulichet, 2005) que se encontra em estado de vulnerabilidade intensa em uma experiência de satisfação. Essa operação, assim, oferece recursos para compreender o enfrentamento do sujeito com a dor proveniente do sentimento de desvalia que beira a angústia de fragmentação corporal. É nessa direção que Le Poulichet (2005) afirma que o padecimento toxicômano está ligado a um período anterior à relação do sujeito com o outro. A autora observa que, sob os efeitos da substância, há a ausência da excitação e da fome, revelando a subtração das atividades desejantes e do reconhecimento, até mesmo, da vigência das funções autoconservativas. Opera-se um atalho referente ao trajeto pulsional no sentido de exclusão do outro e de sua ida e vinda, aderindo a um único objeto que cumpre função vital (Gurfinkel, 2011), um órgão fantasma (Le Poulichet, 2005).

Seguindo a concepção de Savietto (2010), as toxicomanias caracterizam-se pela compulsão à repetição, um tipo peculiar de dependência, um estado de escravidão e de 
deserotização. Ressaltam uma dependência patológica, na qual o sujeito não pode prescindir do objeto droga, eleito na singularidade de sua dinâmica psíquica, marcada pela precariedade do si mesmo e por uma economia psíquica predominantemente tanática. Denicola (2012) inclui nesses pontos essenciais a presença do excesso e da tentativa de controle absoluto de si. Percebe-se, a partir da narrativa de E. que, na toxicomania, o sujeito cria, por meio do consumo exacerbado, uma experiência de alívio de intensidade insuportável ao Eu, criando um circuito narcisista de lidar com a dor, rompendo com os investimentos no semelhante e aderindo a um objeto droga como única estratégia de enfrentamento do desprazer que exclui a alteridade, enaltece as condutas autocentradas e promove o cancelamento das sensações e percepções. A sistemática utilização do objeto droga denuncia a falência do pensamento como recurso mediador das intensidades psíquicas. Espera-se que, no processo de complexização do psiquismo, o pensamento possa ir adquirindo a função de criar novas vias de trâmite das intensidades, de tal forma que as modalidades de prazer e dor encontrem mais recursos de expressão do que os primariamente construídos. O circuito toxicômano de enfrentamento da dor ocasiona o desaparecimento subjetivo por romper as lógicas do desejo e da necessidade, operando compulsivamente como um filtro protetor do psiquismo em relação a estímulos externos e internos (dor ou satisfação). A droga funciona, assim, "como defesa contra a instância simbólica" (Canabarro \& Dagord, 2012, p. 485).

O participante O. (20 anos) conta de seu uso de entorpecentes:

[...] saía do trabalho e ia pras festas, e chegava só no outro dia em casa. Como na última vez que eu usei agora, acho que faz uns 16 dias, saí do serviço às onze e cheguei em casa só às três da tarde de sábado. Tinha virado a noite, usando cocaína e maconha. Tipo, tu sai e os guris oferecem ali, tu nega, eles folgam em ti.

A droga parece servir para dar lugar de valor no mundo, na possibilidade de não se deparar com frustrações próprias da vida: "só sentia prazer, ficava relaxado, ficava bem de boa. Bem tranquilo, esquecia todos os problemas [...] só que aí eu ficava meio depressivo e aí ficava com mais vontade de usar para me sentir melhor". Pode-se recorrer às proposições teóricas de Ribeiro (2009) para identificar em O. o recurso à toxicomania sem a renúncia à inserção no laço social. De fato, a autora afirma existirem duas operações distintas de consumo de drogas: uma delas viabiliza a inserção no laço social, enquanto a outra refere-se à entrega do Eu à morte. O participante 0 . aponta para a primeira das modalidades, uma vez que há um uso vinculado à manutenção das atividades laborais, afetivas e sociais. Essa forma de administração das drogas visa à proteção do Eu de um sujeito contemporâneo que, impedido de encontrar um objeto único que sacie o seu desejo, constitui-se como sujeito faltante, mas utiliza diversos objetos de consumo na tentativa fazer-se pleno, embora reconheça que esse estado é da ordem do impossível. Já P. (24 anos) destaca a segunda das modalidades descritas por Ribeiro (2009). O participante conta que perdeu o controle quando passou a 
consumir crack. Durante uma entrevista, ao relacionar o uso do crack com a história de P., a entrevistadora pergunta:

\author{
Mas aí o crack mudou tua relação com a droga? \\ P.: É, o crack foi agora em 2005 [silêncio]. Agora, modo de dizer. \\ Entrevistadora: Faz seis anos. \\ P.: É... [silêncio]. \\ Entrevistadora: Então, foi concomitante à morte da tua mãe. \\ P.: Agora a senhora me pegou naquela parada.
}

A atemporalidade da dor e a ausência da capacidade de estabelecer conexões denunciam a necessidade de recorrer à droga ante a angústia que não encontra recursos psíquicos para produzir palavras. Conforme Ribeiro (2009), a entrega do Eu à morte se refere ao movimento de desinvestimento do Eu por meio da intoxicação. Nesse cenário, visualizam-se sujeitos que buscam, no encontro com o tóxico, um gozo na completude. Estabelece-se uma relação sem espaço para terceiros, sem adiamentos e fonte de investimento psíquico.

Nessa mesma direção, R. (19 anos) relata o espaço que o objeto droga passou a ocupar após o fim do seu namoro:

Depois que perdi a namorada... eu estava namorando, daí comecei a namorar e larguei tudo por dois anos. Quando ela acabou comigo, comecei a usar, daí não parei mais. Ela [a namorada] era a melhor coisa que eu tinha, a única coisa que eu tinha no mundo. Agora, parece que eu não consigo mais nada nessa vida. Aí era droga e droga. De segunda a segunda, não tinha horário certo, nem tomava café, ia usar droga direto. Tinha vezes que eu nem via a minha mãe; ficava sumido uma semana. Só pensava em usar e usar.

A falta provocada pelo fim do namoro é obturada pela droga, da qual o sujeito não pode mais abrir mão. Parece fundamental marcar o quanto o objeto droga ocupa o lugar de prótese, sem a qual há um colapso do funcionamento psíquico. Afinal, o que R. destaca é que tudo o que tinha se foi e a dor tornou-se insuportável.

\title{
Considerações finais
}

A complexidade da toxicomania demanda considerar a singularidade de cada indivíduo, questões relativas à sua história, às modalidades experienciadas no contexto intersubjetivo, bem como às repercussões identitárias e psíquicas no uso da droga. Constatou-se, no relato dos participantes, a forma como as intensidades vivenciadas precocemente não tramitadas pelo psiquismo encontram, como descarga, a via do ato. Na realidade das toxicomanias, o ato de consumir é uma tentativa de medicar-se diante do insuportável quantum de excitação psíquica. Tal consumo ao mesmo tempo anestesia a dor psíquica e remete à possibilidade da morte, evidenciando a dramática fragilidade do Eu na busca de alternativas diante da vida. Na sobreposição confusa da droga como remédio e como veneno, o sujeito perde a condição de ser o protagonista autônomo de sua história. 
Nos relatos deste estudo, os danosos efeitos da precária condição do outro semeIhante, em seu papel de objeto primordial no processo de construção do sujeito psíquico, são marcados por sua ausência mais do que sua presença, sua indiferença mais do que seu investimento amoroso, seu descuido mais do que seu cuidado. Logo, surgem fraturas na necessária inauguração para o sujeito das experiências de amor e alteridade. Essas condições inaugurais são essenciais para a existência do posterior cuidado consigo e para sua inserção no cenário intersubjetivo. O abandono, o descaso e a hostilidade se apresentam como marcas, quase cotidianas, nas modalidades de relacionamento desses jovens com figuras primordiais ou com outros adultos dos quais dependem afetiva e financeiramente. Ainda, a situação de desemprego, realidade da maior parte dos entrevistados, denuncia também o lugar marginal ocupado por essas pessoas no cenário socioeconômico. Mais uma evidência do empobrecimento em suas possibilidades de ser, na medida em que se percebem aprisionados a esse lugar marginal que os captura e pauta o seu devir na dimensão de uma importante restrição psíquica, social e econômica. Presos à compulsiva repetição, percebe-se, nesses sujeitos, a utilização da estratégia de retorno das intensidades contra si próprios (num processo de introversão libidinal), numa tentativa autoerótica de enfrentamento das demandas de si e do mundo. Na complexa teia que enreda o sujeito e o direciona ao uso das substâncias tóxicas, a presença de relações totalizantes e indiscriminadas o deixa novamente entregue ao desamparo de não poder contar com o outro como vetor de uma função de cuidado, criando uma modalidade de exclusão do investimento libidinal em diversos objetos, empobrecendo os vínculos e incrementando o estado de escravidão ao objeto droga.

A constatação da fragilidade psíquica dos participantes deste estudo permite, ainda mais, reafirmar a necessária ampliação nas estratégias usuais de intervenção sobre o fenômeno da drogadição. As entrevistas evidenciaram que uma intervenção com o método psicanalítico precisa ser construída alicerçada em uma condição de escuta e de cuidado ao sujeito que se encontra aprisionado ao objeto droga, com o intuito de resgatá-lo para uma maior apropriação de seu devir. Quando se atribui a posição de atividade à pulsão e não ao objeto droga, alcança-se uma nova forma de pensar as toxicomanias. Nessa perspectiva, é preciso desenvolver intervenções que visem acolher e transformar o universo pulsional caótico desses sujeitos, os quais evidenciam, a todo tempo, a ausência de recursos complexos de trâmite da energia psíquica e o fracasso nas capacidades de pensamento, de linguagem e da criatividade. Dessa forma, esse circuito intrapsíquico revela uma dinâmica psíquica que aciona intensidades tanáticas e destrutivas, corrompendo o investimento no devir e levando à abolição da condição de sujeito. Logo, o ponto basal do tratamento da toxicomania não está no uso da substância ou no comportamento abstinente, mas na fundamental consideração à posição subjetiva do sujeito diante do objeto droga, sendo vitais as intervenções propulsoras de uma transição nesse posicionamento, de modo que a transformação necessária resulte na construção de novas vias de enfrentamento e tramitação das intensidades psíquicas. 
Como limitações deste estudo, destaca-se a possibilidade de ampliar a faixa etária dos participantes, a fim de contemplar diferentes problemáticas que possam associar-se à condição de toxicomania. Ressalta-se, ainda, a pertinência de capacitar profissionais da saúde para práticas preventivas, na atenção ao papel do cuidado primordial na constituição subjetiva.

\section{Referências}

Campos, L. F. (2001). Métodos e técnicas de pesquisa em psicologia. Campinas: Alínea.

Canabarro, R. C. S., \& D'Agord, M. R. L. (2012). Drug addiction and social discourses. Revista Latinoamericana de Psicopatologia Fundamental, 15(3), 482-496.

Conte, M. (2003). A clínica psicanalítica com toxicômanos: o "corte \& costura" no enquadre institucional. Santa Cruz do Sul: Edunisc.

Denicola, L. (2012). Adicciones, el circuito de un goce mortífero. La Peste de Tebas, 16(51), 15-20.

Erickson, F. (1997). Métodos cualitativos de investigación sobre la enseñanza. In M. Wittrock (Org.). La investigación de la enseñanza (pp. 195-301). Barcelona: Paidós.

Escritório das Nações Unidas sobre Drogas e Crime (2012). World Drug Report 2012. Recuperado em 21 outubro, 2013, de http://www.unodc.org/brazil.

Gurfinkel, D. (2011). Adições: paixão e vício. São Paulo: Casa do Psicólogo.

Hornstein, L. (2008). As depressões: afetos e humores do viver. São Paulo: Via Lettera: Centro de Estudos Psicanalíticos.

Le Poulichet, S. (2005). Toxicomanía y psicoanalisis. Buenos Aires: Amorrortu.

BRASIL. Lei $n^{\circ} 11.343$ (2006). Recuperado em 15 setembro, 2009, de www.planalto. gov.br/ccivil/L11343.htm.

Moraes, E. G., \& Macedo, M. M. K. (2011). Vivência de indiferença: do trauma ao ato-dor. São Paulo: Casa do Psicólogo.

Ribeiro, C. (2009). Que lugar para as drogas no sujeito? Que lugar no sujeito para as drogas? Uma leitura psicanalítica do fenômeno do uso de drogas na contemporaneidade. Ágora, 12(2), 333-346.

Savietto, B. (2010). Drogadição na juventude contemporânea: a "intoxicação" pelo outro. Tese de doutorado, Universidade Federal do Rio de Janeiro, Rio de Janeiro, RJ, Brasil.

Torossian, S. D. (2004). De qual cura falamos? Relendo conceitos. Revista da Associação Psicanalítica de Porto Alegre, 26, 9-15. 